\title{
Increasing prevalence of juvenile onset Type 1 (insulin-dependent) diabetes mellitus in Sardinia: the military service approach
}

\author{
M.Songini ${ }^{1}$, M.Loche ${ }^{1}$,Sa.Muntoni ${ }^{1}$, M.Stabilini ${ }^{1}$, A. Coppola ${ }^{2}$, G. Dessi ${ }^{2}$, A. Green ${ }^{3}$, G.F.Bottazzo ${ }^{4}$, Se.Muntoni $^{1}$ \\ ${ }^{1}$ Center for Metabolic Diseases, San Michele Hospital, Cagliari, Italy \\ ${ }^{2}$ Military Hospital, Cagliari, Italy \\ ${ }^{3}$ Genetic Epidemiology Research Unit, Odense, Denmark \\ ${ }^{4}$ Department of Immunology, The London Hospital Medical College, London, UK
}

Summary. In order to obtain new and more detailed information about temporal trends and geographic distribution of Type 1 (insulin-dependent) diabetes mellitus in Sardinia, we screened a series of birth cohorts (1936-1973) of all male army conscripts aged 18-19 years, filed in the Sardinian Conscript Register where Type 1 diabetes is a cause of rejection. A total of 678 diabetic subjects, born and permanently residing in Sardinia, was identified. The point prevalence $(\times 1000)$ at the age of 20 years in the birth cohorts ranged from values close to zero for the first ten cohorts (1936-1945) up to a maximum of 3.08 (95\% confidence limits $2.28-4.08$ ) for the 1966 cohort and continued high thereafter although an apparent decrease was observed from the early 1970s birth cohorts. Type 1 diabetes was distributed throughout the four provinces of Sardinia with no particularly significant hete- rogeneity; however, in accordance with the geographical distribution of diabetes cases of the Eurodiab Ace survey (1989-1990), the highest prevalence of the disease was observed in the Cagliari and Oristano provinces, followed by Nuoro and Sassari. These data suggest a gradually increasing trend of male Type 1 diabetes prevalence in Sardinia with a 29-fold increase between the late 1930s and the late 1960s birth cohorts. This seems to confirm the high incidence of Type 1 diabetes in the 0-14 and 0-29 year age groups recently reported among Sardinians during the Eurodiab Ace collaborative multicentre study.

Key words: Type 1 (insulin-dependent) diabetes mellitus, geographical distribution, trends, point prevalence, Sardinia, conscript registers.
The incidence of Type 1 (insulin-dependent) diabetes mellitus, one of the most common chronic diseases with onset early in life, has been increasing in Europe during the past 20 years and a considerable geographic variation has been recently described [1] with a 10-fold difference between the lowest and the highest rates. Recently, the Eurodiab Ace multinational collaborative project has confirmed the striking and surprising unique diabetes hotspot of Sardinia, whose figures $(30.2 / 100,000$ for the 0 14 year age group and $24 / 100,000$ for the $0-29$ year age group in 1989 and 1990) have approached the estimates of incidence observed in Finland [2-4]. Higher than expected incidence $(24 / 100,000)$ and prevalence $(1.58 / 1000)$ rates have also been previously assessed in the province of Cagliari (southern Sardinia) between 1984 and 1986 in the 0-18 year age group [5]. Moreoever, a retrospective analysis of the Sardinian newly-diagnosed Type 1 diabetic patients aged 0-14 years between 1958 and 1987, but lacking a secondary validation source, showed a sharp increase in the incidence of the disease with two outbreaks in 1975 and 1983 and generally a doubling or even trebling every 10 years [6]. These results strongly substantiate the exis- tence of an environmental contribution to the aetiology of Type 1 diabetes in general [7] and specifically in Sardinia.

In order to obtain new and more detailed information data and to characterize the temporal trend and the geographical distribution of the prevalence of juvenile onset Type 1 diabetes in Sardinia we carried out an analysis of a series of birth cohorts (1936-1973) of Sardinian male army conscripts aged 0-19 years, rejected because of Type 1 diabetes.

\section{Subjects, materials and methods}

\section{Ascertainment and verification of cases}

According to the Italian law all male citizens must appear before a Conscript Board for a clinical examination and a thorough assessment prior to military or civil service. The first examination takes place between the age of 18-19 years at the latest and cannot be postponed. Only the military duty can be postponed upon request (generally until 26 years of age) e.g. for completion of study. A second conscript examination can take place upon request before military duty is started. Subjects who leave before the age of the conscript examination must return to Sardinia for the examination 
Table 1. Overview of the study material (grouped birth cohorts)

\begin{tabular}{|c|c|c|c|c|c|c|c|c|c|}
\hline Birth cohort (year) & $1936-1940$ & $1941-1945$ & $1946-1950$ & $1951-1955$ & $1956-1960$ & $1961-1965$ & $1966-1969$ & $1970-1973$ & Total \\
\hline Primary number of cases & 10 & 3 & 58 & 88 & 103 & 132 & 183 & 158 & 735 \\
\hline \multicolumn{10}{|l|}{ Exclusion criteria: } \\
\hline Born outside Sardinia & 1 & 0 & 0 & 5 & 1 & 3 & 8 & 25 & 43 \\
\hline Age: $>20$ & 3 & 2 & 3 & 2 & 1 & 2 & 1 & 0 & 14 \\
\hline Final number & 6 & 1 & 55 & 81 & 101 & 127 & 174 & 133 & 678 \\
\hline \multicolumn{10}{|l|}{ Age conscript examination (years) } \\
\hline 18 & 3 & 0 & 0 & 0 & 23 & 116 & 138 & 122 & 402 \\
\hline 19 & 0 & 0 & 31 & 70 & 71 & 10 & 30 & 8 & 220 \\
\hline 20 & 3 & 1 & 24 & 11 & 7 & 1 & 6 & 3 & 56 \\
\hline Liveborn males & 82313 & 82162 & 89061 & 87280 & 87336 & 84818 & 64626 & 60695 & 638291 \\
\hline Number of deaths before age 20 & 15398 & 15856 & 11811 & 8095 & 6331 & 5238 & 3483 & 2743 & 68955 \\
\hline Cohorts & 66915 & 66306 & 77250 & 79185 & 81005 & 79580 & 61143 & 57952 & 569336 \\
\hline Point prevalence $\times 1000$ & 0.089 & 0.015 & 0.71 & 1.02 & 1.25 & 1.60 & 2.85 & 2.30 & 1.19 \\
\hline $95 \%$ confidence limits & $0.033-0.2$ & $0.004-0.08$ & $0.54-0.93$ & $0.81-1.27$ & $1.02-1.52$ & $1.33-1.90$ & $2.44-3.30$ & $1.92-2.72$ & $1.10-1.30$ \\
\hline
\end{tabular}

Test of linear trend: total chi-square $(d f=7), 373.61, p<0.0005$.

chi-square $(d f=1)$ due to linear regression, 334.56 .

chi-square $(d f=6)$ due to departure from linear regression, $39.05, p<0.0005$.

before their 21 st birthday at the latest, in order to be allowed to definitely move from the island. However, those who move permanently to mainland Italy before 18-19 years of age are examined by the conscript board of the new residence. For obvious logistical reasons it is impossible to account for these cases.

Sardinia has only one conscript board district in Cagliari where subjects liable for military service are examined. For several decades the examination and administration of registers have followed the same guidelines all over the island. In addition to personal data on each subject, a medical record for those rejected is established. During investigation of the files of the Sardinian Conscript Register we identified all the males who were 1) born in Sardinia between 1 January 1936 and 31 December 1973 and 2) were rejected by the Conscript Board because of a diagnosis of idiopathic diabetes. The study was closed in December 1991 at which time the youngest subject in the cohort had reached the age of 18 years. Subjects previously diagnosed with diabetes, certified by a physician, will inevitably be rejected with diabetes listed as the reason. Moreover, the conscript board register records the date and place of birth, present address, time and place of the examination, all available medical certificates, the insulin treatment and the genetic conditions to which diabetes among Sardinians might be secondary (e.g. thalassaemia), but no information is available for the date of onset of the disease. In each initial case of diabetes or suspected diabetes (glycosuria, renal glycosuria, latent diabetes, renal diabetes) recorded at the board examination, in order to confirm the diagnosis, a compulsory additional medical investigation was performed during admission to the Cagliari Military Hospital.

\section{Population data}

Data on the number of liveborn males from the cohorts under study were obtained from official statistical reports (Istituto Centrale di Statistica ISTAT, Regione Autonoma Sardegna). From these sources it has also been possible to assess the number of deaths ( 0 19 year age group, males) and the emigration level (male and female, all ages) in both the Italian and Sardinian population for the relevant period. Death certificates were not available for study.

No difference was found between Sardinian and Italian mortality rates; therefore, we subtracted all deaths occurring before the age of 19 years among the Sardinian birth cohorts and then estimated the number of subjects at risk of diabetes from birth to the age of con- scription. The subtraction was done to outweigh the omission of in dividuals who might have died before the age of conscription [8].

On the other hand, the analysis of Sardinian emigration data and their comparison with data from Italy was done in order to obtain a rough estimate of the phenomenon, being almost impossible to obtain from official sources the number of Sardinian males aged 0 20 years who emigrated during the study period.

\section{Statistical analysis}

The basic epidemiological measure of occurrence employed in this analysis was the prevalence of diabetes at age 20 years. In addition to representing a point prevalence by age 20 years, this measure estimates the risk of developing diabetes before 20 years of age, assuming that excess mortality among diabetic subjects may be ignored before that age. Since age-specific prevalence represents a proportion, confidence intervals for point prevalences were estimated by means of the Poisson distribution. Chi-square analyses were used for testing heterogeneity between proportions and for the analysis of time trends the method of Armitage [9] was employed.

\section{Results}

In the conscript register 735 subjects with Type 1 diabetes were identified (Table 1). Forty-three subjects (5.8\%) were excluded because they were born outside Sardinia. An additional 14 subjects $(1.9 \%)$ were excluded because they were older than 20 years at the time of the second conscript examination where they were rejected because of Type 1 diabetes. After reduction by cases not fulfilling the inclusion criteria, 678 subjects $(92.2 \%)$ remained. The initial cohorts have been subtracted by deaths. The increase of prevalence in the grouped (5-year) birth cohorts was 29-fold over the 37 year (1936-1973) birth cohort period. This non-linear trend can be divided by a comparison of the $95 \%$ confidence limits (Poisson distribution) into three main periods: a plateau of low, although nonsignificant, prevalence rates recorded for the first two grouped (5-year) birth cohorts (1936-1945), an increase 


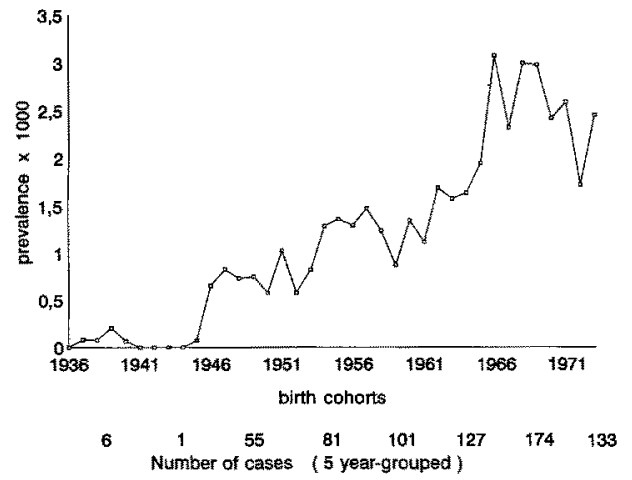

Fig. 1. Military conscript registry. Point prevalence $(\times 1000)$ of Type 1 diabetes at 20 years in Sardinian 1936-1973 male birth cohorts

for the 1946-1965/1969 birth cohorts and an apparent plateau/decrease for the 1966/1969-1973 birth cohorts.

The 1961-1965 and 1966-1969 birth cohorts have a significantly higher rate compared with the previous cohorts, reaching a peak value of $2.85 / 1000$ for the late $1960 \mathrm{~s} \mathrm{co-}$ horts, close to the rates reported for Nordic countries. The chi-square analysis of the birth cohorts, according to 5year grouping by date of birth, shows that there is definitely a significant variation according to the birth cohorts although, over the total period of observation, this variation does not fit a linear trend. This increased prevalence that fails to fit into a linear trend is also clearly illustrated in Figure 1 which also shows the distribution at the time of examination for cases from the conscript register.

Figure 2 illustrates the different provincial trends for the prevalence of Type 1 diabetes among Sardinian birth cohorts. Figure 3 shows the four provinces of Sardinia. The geographic distribution of patients in the provinces of Sardinia is shown in Table 2 with reference to the date of birth (it must be noted that in 1976 the Cagliari province split administratively into two, Cagliari and Oristano). The relative distribution at birth is in agreement with the corresponding distribution of the total birth cohorts under study. Unfortunately, it has not been possible from official sources to assess the number of deaths at provincial level which restricted our analysis of prevalence (this holds also for Fig.2) in comparison with the figures given in Table 1. The traditional chi-square analysis of these data has been performed in two dimensions: a) according to birth cohorts within region as well as for Sardinia as a whole (the latter being similar to the overall chi-square value in Table 1, but with slightly different denominators and with fewer groups); b) according to provinces within each subcohort as well as total cohort. It can be seen that for all provinces and for Sardinia as a whole (as already shown in Table 1), the statistical evidence of heterogeneity among the cohorts is overwhelming with the Cagliari-Oristano province showing the highest prevalence rate, followed in order by Sassari and Nuoro. However, there is no major support for geographic heterogeneity, except for the fact that the very early cohorts of the Nuoro province (the wildest, most isolated and sparsely populated Sardinian geographical area) has such a low prevalence rate $[0.07(95 \%$ confidence limits $0.01-0.2)$ ] that it almost approaches a $p$-value close to the $5 \%$ level.

\section{Discussion}

During the past few years the changing patterns of Type 1 diabetes have been much researched [10-13]. The principal aim of the present study was to characterize the secular trend of the recently reported high incidence of Type 1 diabetes in Sardinia $[1,2,5,6]$.
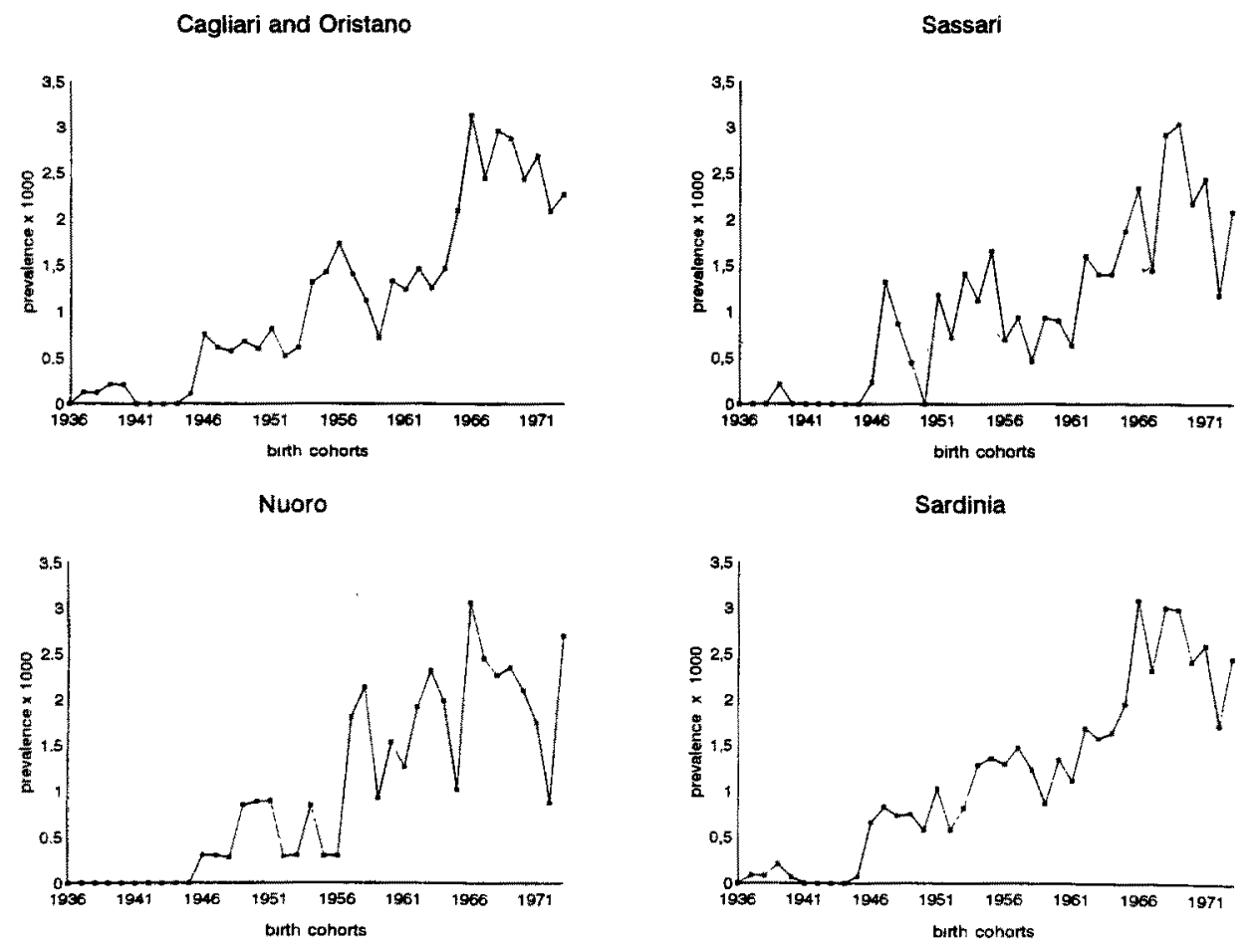

Fig. 2. Military conscript registry. Point prevalence $(\times 1000)$ of Type 1 diabetes in 1936-1973 male birth cohorts from the different provinces of Sardinia 


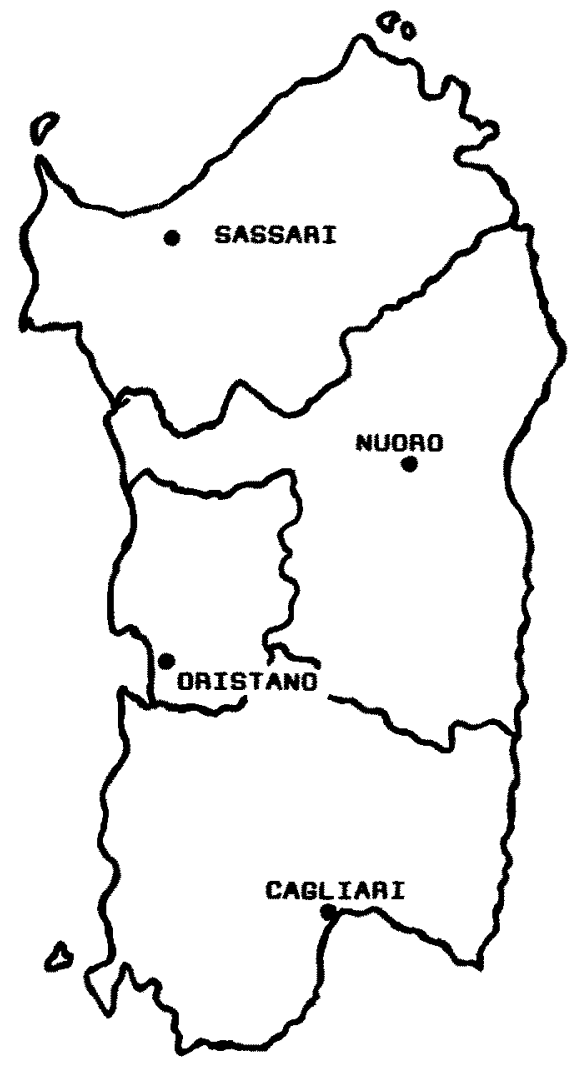

Fig. 3. Map of Sardinia showing the four provinces

To this purpose, the conscript board register of Sardinia represented a valuable, well-documented source, although previously never used locally, for epidemiological studies of diabetes (or probably of other easily-defined childhood chronic diseases) occurring during the first 20 years of life [10-13]. The unique Sardinian register covers all young males irrespective of their health status or their eventual later exemption from military duty. All conscript files have been handled according to the same rules for several decades. Finally, Sardinia, as a large isolated Mediterranean island, represents an ideal basis for epidemiological studies because of a) the homogeneous, stable and genetically well-defined population of $1.6 \mathrm{mil}-$ lion people, b) the uniform widespread health care services and c) access to vital statistics and public registers.

Our study shows that the point prevalence rate of Type 1 diabetes in the total birth cohorts (1936-1973) for those aged 20 years is 1.19 per 1000 ( $95 \%$ confidence limits $1.10-1.28$ ) with a significant non-linear increase in prevalence with increasing birth cohort showing an apparent maximum at the end of the 1960s. Other studies have reported similar findings [14-18]; for instance, Green et al. [16] described a significant increase in incidence of diabetes among Danish males aged 0-19 years reaching an apparent maximum at the beginning of the 1970s. On the other hand, studies of the incidence for birth cohorts from the United States [19], Poland [10], Sweden [20] and Finland [21] failed to do so. As we have already discussed, unexpectedly high incidence $(24 / 100,000)$ and prevalence $(1.58 / 1000)$ rates (however lacking secondary validation sources and circumscribed only to the province of Caglia- ri) for individuals aged $0-18$ years have been recorded in Sardinia during 1983-1986 [5]; a sharp rise in the trend has also been confirmed in a retrospective study covering the 30-year period 1958-1987 [6], where a progressive rise in the incidence of Type 1 diabetes during the same period among Sardinian subjects aged $0-14$ years was recorded. The present study does not explain this secular trend. Given the absence of a secondary validation source for the whole study period, improved survival after the 1950s birth cohorts and a more precise and accurate ascertainment of Type 1 diabetes through better health care could partially explain the 1936-1945 birth cohort low plateau and the sudden increase of the 1946-1965/1969 birth cohorts. (It must be stressed that between 1955 and 1987 the national stillbirth, perinatal, and first-year mortality rates declined by about $80 \%$ with no noticeable reduction in the rates between the Northern, Central and Southern, [including Sardinia] areas of Italy.) Moreover, emigration from Sardinia reached its peak between the early 1950s and the early 1960s (corresponding to the 1930-1940s birth cohort) simultaneously with the registered low prevalence of the disease and therefore could represent one of the possible reasons for the observed trends. Still Sardinians who left before the age of the conscript board examination (18-19 years) generally had to be examined in Sardinia before the age of 21 in order to be allowed to move from the island. People who permanently moved to the mainland were mostly those who left in search of employment at an age generally older than 18-19 years to the more industrialized northern regions of Italy (Piedmont, Lombardy). Therefore, the error introduced is probably small. In order to better define this possible confounding bias, we have already set up a Sardinian migrant study to ascertain the prevalence and possibly the cumulative incidence of Type 1 diabetes among the Sardinian migrant communities around Italy and Europe. Lastly, the ongoing registration of a) new Type 1 diabetic patients, as part of the collaborative Eurodiab Ace study and b) the annual screening of the Sardinian Conscript Register will enable us to better characterize the phenomenon of the reported high frequency of the disease among Sardinians. The estimated point prevalence after the mid-1950s birth cohorts, assuming no major changes in the mortality rate before age 20 years, will be very similar to the cumulative incidence and can be interpreted as the average risk of developing Type 1 diabetes from birth to age 19 years. We have no obvious explanation as to the small rates in the oldest cohorts. Type 1 diabetes was distributed throughout the different provinces of Sardinia according to the distribution of the total birth cohorts without any particular significant heterogeneity. However, with all due reservations, it must be stressed the rapidly rising prevalence, of the wild, rural and more isolated province of Nuoro (east) - with the lowest total prevalence rate - compared to the higher rates observed in both the more urbanized provinces of Cagliari-Oristano (south-west), with the highest rate and the Sassari province (north) at the intermediate level. This finding is also in accordance with the provincial distribution of newly-diagnosed Type 1 diabetic patients recorded during the Eurodiab Ace survey, carried out from 1989 through 1990, that showed a 
Table 2. The distribution of birth cohorts by place of residence within provinces of Sardinia at the time of birth

\begin{tabular}{|c|c|c|c|c|c|c|}
\hline \multirow[b]{2}{*}{ Cases } & \multicolumn{4}{|l|}{ Year of birth } & & \\
\hline & $1936-1948$ & $1949-1960$ & 1961-1973 & Total & & \\
\hline \multicolumn{7}{|l|}{ Provinces } \\
\hline $\begin{array}{l}\text { Oristano + } \\
\text { Cagliari }^{\mathrm{a}}\end{array}$ & $\begin{array}{c}7+ \\
20\end{array}$ & $\begin{array}{l}26+ \\
95\end{array}$ & $\begin{array}{c}37+ \\
222\end{array}$ & $\begin{array}{l}70+ \\
337\end{array}$ & & \\
\hline Sassari & 12 & 45 & 103 & 160 & & \\
\hline Nuoro & 3 & 37 & 71 & 111 & & \\
\hline Sardinia & 42 & 203 & 433 & 678 & & \\
\hline \multicolumn{7}{|c|}{ Birth cohorts } \\
\hline $\begin{array}{l}\text { Oristano + } \\
\text { Cagliari }^{\mathrm{a}}\end{array}$ & 114602 & 118118 & 119376 & 352096 & & \\
\hline Sassari & 58026 & 52005 & 55220 & 165251 & & \\
\hline Nuoro & 44855 & 40546 & 35543 & 120944 & & \\
\hline Total & 217483 & 210669 & 210139 & 638291 & & \\
\hline \multicolumn{5}{|c|}{ Point prevalence $\times 1000(95 \%$ confidence limits $)$} & $\begin{array}{l}\text { Chi-square, time } \\
(d f=2)\end{array}$ & $p$-value \\
\hline $\begin{array}{l}\text { Cagliari + } \\
\text { Oristano }^{a}\end{array}$ & $\begin{array}{l}0.24 \\
(0.16-0.34)\end{array}$ & $\begin{array}{l}1.02 \\
(0.85-1.22)\end{array}$ & $\begin{array}{l}2.17 \\
(1.91-2.45)\end{array}$ & $\begin{array}{l}1.16 \\
(1.05-1.27)\end{array}$ & 191.86 & $<0.00001$ \\
\hline Sassari & $\begin{array}{l}0.21 \\
(0.11-0.36)\end{array}$ & $\begin{array}{l}0.87 \\
(0.63-1.16)\end{array}$ & $\begin{array}{l}1.87 \\
(1.52-2.26)\end{array}$ & $\begin{array}{l}0.97 \\
(0.82-1.13)\end{array}$ & 81.21 & $<0.00001$ \\
\hline Nuoro & $\begin{array}{l}0.07 \\
(0.01-0.20)\end{array}$ & $\begin{array}{l}0.91 \\
(0.64-1.26)\end{array}$ & $\begin{array}{l}2.00 \\
(1.56-2.52)\end{array}$ & $\begin{array}{l}0.92 \\
(0.75-1.11)\end{array}$ & 80.54 & $<0.00001$ \\
\hline Sardínia & $\begin{array}{l}0.19 \\
(0.14-0.26)\end{array}$ & $\begin{array}{l}0.96 \\
(0.84-1.11)\end{array}$ & $\begin{array}{l}2.06 \\
(1.87-2.26)\end{array}$ & $\begin{array}{l}1.06 \\
(0.98-1.15)\end{array}$ & 353.75 & $<0.00001$ \\
\hline $\begin{array}{l}\text { Chi-square } \\
\text { (province) }\end{array}$ & 4.83 & 1.08 & 1.78 & 6.65 & & \\
\hline $\begin{array}{l}p \text {-value } \\
(d f=2)\end{array}$ & $0.05<p<0.10$ & $p>0.05$ & $p>0.05$ & $p<0.05$ & & \\
\hline
\end{tabular}

${ }^{a}$ Divided into two administrative provinces after 1976

cluster (hot spot) of the disease in the Cagliari and Oristano provinces, where the highest incidence ( $0-29$ years) rates were recorded, followed respectively by Nuoro and Sassari. Furthermore, these data do not seem to geographically overlap with the prevalence of islet cell antibodies (ICA) (a marker of beta-cell autoimmunity and probably of pre-Type 1 diabetes) in healthy male school children that we have recently [22] assessed in three of four provinces of Sardinia (Cagliari, Oristano, Nuoro) and who showed the lowest ICA prevalence in Oristano.

In conclusion, we have found that the point prevalence of Type 1 diabetes before age 20 years in Sardinian males has sharply increased during the past 20 years apparently during the late 1960 s reaching a peak close to the values reported for Nordic countries [1,2,17,23-25]. Apparently, the geographical distribution of the prevalence of the disease did not exhibit any particular heterogeneity. Moreover, our data seem to confirm similar trends described retrospectively from 1958 to 1987 for the incidence and prevalence of the disease among Sardinian individuals aged $0-14$ years [6].

Acknowledgements. M.L. was supported during this study by a research fellowship of the ASRIS (Sardinian Association for the Study of Type 1 Diabetes Mellitus). The authors are indebted to Ms. A. Loche for the invaluable software assistance; Lieutenant Colonel M. Granata and Warrant officer A.Mereu, Barracks Ederle, Caglia- ri, for their role in conscript data collection; the ISTAT of Rome and Cagliari offices for the demographical data; Dr. A. Aledda of the Regione Autonoma Sardegna (RAS) for emigration data. We also wish to thank Dr. E.A.M. Gale, London (UK) and Dr. G.J.Bruining, Rotterdam (The Netherlands) for helpful suggestions for this study. The study was presented in part at the EASD 28th Annual Meeting held in Prague, 7-12 September 1992.

\section{References}

1. Diabetes Epidemiology Research International Group (1988) Geographic pattern of childhood insulin-dependent diabetes mellitus. Diabetes 37: 1113-1119

2. Green A, Gale EAM, Patterson CC for the EURODIAB ACE Study Group (1992) Incidence of childhood-onset insulin-dependent diabetes mellitus: the Eurodiab Ace study. Lancet 339: 905-909

3. Songini M, Muntoni S (1991) High Incidence of type 1 diabetes in Sardinia. Lancet 337: 1047

4. Muntoni S, Songini $M$ and the Sardinian Collaborative Group for Epidemiology of IDDM (1992) High incidence rate of IDDM in Sardinia. Diabetes Care 15: 1317-1322

5. Diabetes Epidemiology Research International (DERI) Study Group (1990) The epidemiology and immunogenetics of IDDM in Italian-heritage populations. Diabetes Metab Rev 6: 63-69

6. Silvetti M, Angius E, Pusceddu P et al. (1990) Epidemiology of juvenile diabetes in Sardinia. J Endocrinol Invest 13 [Suppl 3]: 83 (Abstract) 
7. Green A (1990) The role of genetic factors in development of insulin dependent diabetes mellitus. In: Baekkeskov S, Hansen $B$ (eds) Human diabetes. Genetic, environmental and autoimmune etiology. Current topics in microbiology and immunology, Vol.164. Springer, Berlin, Heidelberg, New York, pp 3-16

8. Green A, Andersen PK (1983) Epidemiological studies of diabetes mellitus in Denmark: 3. Clinical characteristics and incidence of diabetes among males aged 0 to 19 years. Diabetologia 25:226-230

9. Armitage P (1971) Statistical methods in medical research. Blackwell Scientific Publications, Oxford

10. Rewers M, LaPorte RE, Walczak M, Dmochowski K, Bogaczynska E (1987) An apparent 'epidemic' of youth onset insulin-dependent diabetes mellitus in midwestern Poland. Diabetes 36: 106-113

11. Dahlquist G, Blom L, Holgren G, Hogglof B, Larsson Y, Sterkey $G$ (1985) The epidemiology of diabetes mellitus in Swedish children 1-14 years: a six year prospective study. Diabetologia 28: 802-808

12. LaPorte RE, Fishbein HA, Drash AL et al. (1981) The Pittsburgh insulin-dependent diabetes mellitus (IDDM) registry: the incidence of insulin-dependent diabetes mellitus in Allegheny County, Pennsylvania (1965-1976). Diabetes 30: 279-284

13. Tan MH, Worrell MC, Beck AW (1981) Epidemiology of diabetes on Prince Edward Island. Diabetes Care 4: 519-524

14. Kark JD, Kedem R, Revach M(1986) Medical examination of Israeli 17 -year-olds before military service as a national resource for health information. Isr J Med Sci 22:318-325

15. Green A, Hauge M, Holm NV, Rasch LL (1980) Epidemiological studies of diabetes mellitus in Denmark. I. A case finding method based on the national service conscript registry. Diabetologia 19: $355-358$

16. Green A, Andersen PK, Svendsen AJ, Mortensen K (1992) Increasing incidence of early onset type 1 (insulin-dependent) diabetes mellitus: a study of Danish male birth cohorts: Diabetologia 35: 178-182

17. Drykoningen CEM, Mulder ALM, Vaandrager GJ, LaPorte RE, Bruining GJ (1992) The incidence of male childhood type 1 (in- sulin-dependent) diabetes mellitus is rising rapidly in the Netherlands. Diabetologia 35: 139-142

18. Molbak AG, Norgaard K, Christau B, Kiaer M, Nerup J (1987) Incidence of type 1 (insulin-dependent) diabetes mellitus in Denmark - evidence of secular trend. Diabetologia 30: $559 \mathrm{~A}$ (Abstract)

19. Diabetes Epidemiology Research International Group (1990) Secular trends in incidence of childhood insulin-dependent diabetes (IDDM) in ten countries. Diabetes 39: 858-864

20. Nystrom L, Dahlquist G, Rewers M, Walls S (1990) The Swedish childhood diabetes study. An analysis of the temporal variation in diabetes incidence 1978-1987. Int J Epidemiol 19: 141-146

21. Reunanen A, Akerblom HK (1986) A national drug register as a source in the study of the epidemiology of IDDM children in Finland. In: Serrano-Rios M, Lefebvre PJ (eds) Diabetes, 1985. Elsevier, Amsterdam, pp 408-412

22. Muntoni Sa, Loviselli A, Martino E et al. (1992) High prevalence of islet cell antibodies (ICA) in healthy schoolchildren in Sardinia. Diabetologia 35 [Suppl 1]: $32 \mathrm{~A}$ (Abstract)

23. Rewers M, LaPorte RE, King H, Tuomilehto J (1988) Trends in the prevalence and incidence of diabetes: insulin-dependent diabetes mellitus in childhood. World Health Statist Quart 41: 179-189

24. Tuomilehto J, Rewers M, Reunanen A et al. (1991) Increasing trend in Type 1 (insulin-dependent) diabetes mellitus in childhood in Finland. Diabetologia 34: 282-287

25. Vaandrager GJ, Bruining GJ, Veenhof FJ, Drayer NM (1984) Incidence of childhood diabetes in the Netherlands: a decrease from north to south over North-Western Europe. Diabetologia 27: $203-206$

Received: 12 October 1992

and in revised form: 19 February 1993

Dr. M. Songini

Centro Malattie Dismetaboliche

Ospedale S. Michele

I-09134 Cagliari

Italy 